\title{
Mapping Tokyo Olympics 3.0: Archaeologies of the Future
}

\author{
Sharon Hayashi ${ }^{a}$, Elina Lex ${ }^{b}$ \\ ${ }^{a}$ Department of Cinema and Media Arts, York University, Toronto, Canada, hayashi@yorku.ca \\ ${ }^{b}$ Communication Studies, Concordia University, Montreal, Canada, lexelina@gmail.com
}

Keywords: Tokyo, Displacement, Olympics, Mapping, Sensory Archive

\begin{abstract}
:
Mapping Tokyo Olympics 3.0 is a collaborative sensory archive of demolition and displacement surrounding the three Tokyo Olympics. Understanding the Olympics as a cyclical 'practice of subtraction,' where the city is not only rebuilt but unbuilt, we uncover the intertwined layers of the urban development history of these Games and the imperial (1940), high-growth (1964) and post-growth (2020/2021) periods they represent. The first phantom Tokyo Olympics were cancelled due to the war, the second held following massive protests against the US-Japan Security Treaty, and the third postponed by the global pandemic and haunted by the Fukushima nuclear disaster.

Mapping the politics of demolition and displacement exposes the physical effects of the Olympics on the urban landscape of Tokyo as well as the displacement of vulnerable and precarious persons. Using a hybrid spatial-sensory ethnography and intermedial approaches Mapping Tokyo Olympics 3.0 is a sensory archive of the lived experience of displacement that incorporates local knowledge and collaborative research-creation methodologies. A focus on specific sites leads us to consider changing forms of surveillance and labour, while an examination of local and international pressures being exerted on these spaces suggests ways that local contestations of power can be made visible through mapping. Combining methods of 360-degree video, sound recording, and archival resources, we uncover layers of time, history and materiality as we work with local knowledge, embrace contingencies and envision social futures. The sensory mapping archive becomes an archaeology of the future.
\end{abstract}

Bibliography

Easterling, Keller. Subtraction. Berlin: Sternberg Press, 2014. 